
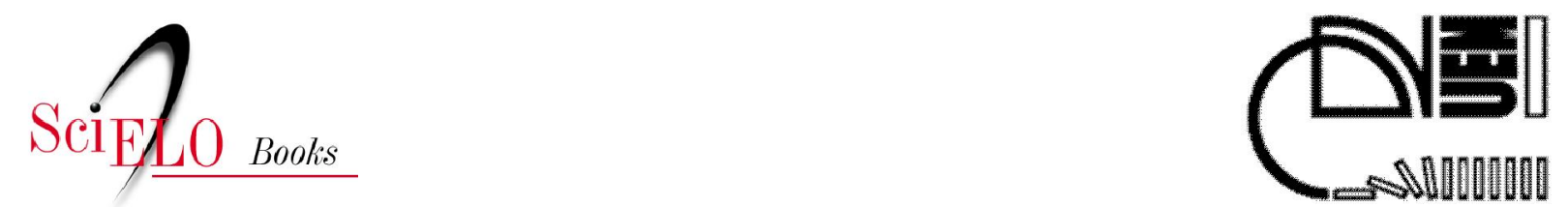

\title{
12 O Partido Comunista e os movimentos sociais no campo
}

\author{
Angelo Priori \\ Luciana Regina Pomari \\ Silvia Maria Amâncio \\ Veronica Karina Ipólito
}

\section{SciELO Books / SciELO Livros / SciELO Libros}

PRIORI, A., et al. História do Paraná: séculos XIX e XX [online]. Maringá: Eduem, 2012. O Partido Comunista e os movimentos sociais no campo. pp. 159-177. ISBN 978-85-7628-587-8. Available from SciELO Books $<$ http://books.scielo.org $>$.

\section{(9)(1)(0)}

All the contents of this chapter, except where otherwise noted, is licensed under a Creative Commons Attribution-Non Commercial-ShareAlike 3.0 Unported.

Todo o conteúdo deste capítulo, exceto quando houver ressalva, é publicado sob a licença Creative Commons Atribuição Uso Não Comercial - Partilha nos Mesmos Termos 3.0 Não adaptada.

Todo el contenido de este capítulo, excepto donde se indique lo contrario, está bajo licencia de la licencia Creative Commons Reconocimento-NoComercial-CompartirIgual 3.0 Unported. 


\section{2}

\section{O Partido Comunista e os movimentos sociais no campo}

No Paraná do século XX, as décadas de 1950 e 1960 foram intensas para os movimentos sociais. Nesses anos, diversos grupos e forças sociais se organizaram, segundo José de Souza Martins, visando à libertação do país da "tutela das oligarquias e do atraso econômico, social e político que elas representavam" (1989, p. 46).

Um desses movimentos surgiu no campo, na forma de organização de sindicatos de trabalhadores rurais. Já vimos neste livro que os homens do campo paranaense sempre estiveram na linha de frente dos embates sociais mais importantes, como foram os exemplos das revoltas camponesas de Porecatu e do Sudoeste. Vimos também que, desde o início da década de 1940, já havia ligas camponesas e associações rurais organizadas no Norte do Paraná. Das Ligas para os Sindicatos, o passo foi curto.

Data de 29 de Janeiro de 1956 o surgimento do primeiro sindicato de trabalhadores rurais do Norte do Paraná. Embora tivesse sido fundado na cidade de Londrina, seu raio de atuação e influência ia além das fronteiras do município. Nesse mesmo ano, foram fundados sindicatos em Nova Fátima, Centenário do Sul e Maringá.

Como surgiram os sindicatos? Seria apenas o desdobramento em nível regional de uma tendência que vinha se fortalecendo em nível 
nacional, no final da década de 1950? Ou haveria algo mais insinuante, que mobilizasse o trabalhador à sindicalização? Pensamos que ambas as hipóteses são válidas e se inter-relacionam. Num panorama em que temos, de um lado, a influência importante da fundação de uma entidade nacional, coordenadora do movimento dos trabalhadores rurais: a União dos Lavradores e Trabalhadores Agrícolas do Brasil (ULTAB), em 1954; e de outro, a desestruturação das relações de trabalho, há muito arraigadas no contexto cultural do homem do campo.

Como vimos no capítulo 08, temos que considerar que a desestruturação do colonato, o fim da agricultura de subsistência e a cobrança do aluguel de moradia exerceram uma força desestruturante, tornando piores as condições de vida do trabalhador rural. A partir do momento em que o proprietário não mais concedeu a possibilidade de o colono plantar intervalarmente aos cafezais gêneros alimentícios, ou então, destinar 'terras solteiras' para essa atividade, e passou a cobrar o aluguel da residência, o colono deparou-se apenas com o salário como única fonte de renda. Com isso então, ao invés de plantar e colher, teria que comprar os produtos básicos para sua alimentação e de sua família.

Outro ponto importante que contribuiu para a desestruturação do colonato foi a política implementada pelo Instituto Brasileiro do Café (IBC), por meio do Grupo Executivo da Racionalização da Agricultura (GERCA), no início dos anos 1960, que montou seu plano diretor baseado em três objetivos básicos: eliminação dos cafeeiros de baixo rendimento; destinação das terras liberadas a outro uso, sobretudo para culturas alimentares e matérias primas industriais, como o soja, milho e trigo; e modernização das plantações cafeeiras restantes. O programa foi elaborado por meio de incentivos aos proprietários, que obtinham empréstimos no Banco do Brasil para o financiamento da maior parte dos custos da erradicação (após terminada a erradicação, esses financiamentos se convertiam em doações) e empréstimos em condições favoráveis para a diversificação com outras culturas. Era uma política que gerava um alto índice de desemprego no Paraná. 
Foi esse processo de desestruturação das relações sociais de trabalho, sobretudo do colonato, que permitiu aos trabalhadores rurais do Norte do Paraná mobilizar seus membros em torno de interesses comuns. Essa identidade coletiva foi sendo construída por meio da organização dos trabalhadores em sindicatos. Estrategicamente, a criação do órgão de representação assegurava ao trabalhador rural um espaço de luta contra essas novas relações que estavam se estabelecendo. Nesse sentido, o surgimento do sindicato foi muito mais uma necessidade social dos trabalhadores do Paraná do que propriamente um movimento nacional que se desdobrou na região. Aliás, o sindicato dos trabalhadores de Londrina foi um dos primeiros a se organizar no Brasil.

\section{Os primeiros sindicatos}

No processo de preparação da II Conferência Nacional dos Trabalhadores Agrícolas (II CNTA), foram criados, em todo o País, 16 sindicatos de trabalhadores rurais. No Estado do Paraná, tem-se notícia da organização de duas associações de empreiteiros e sitiantes (TERRA LIVRE, 1954). No entanto, o primeiro sindicato que se constituiu data de janeiro de 1956, na cidade de Londrina, Norte do Estado.

Ao surgimento do órgão de representação no Norte do Paraná, antecipou-se, entre os trabalhadores rurais, uma ampla discussão acerca das condições de vida e de trabalho. Os baixos salários e as constantes privações a que eram submetidos acabaram possibilitando aos trabalhadores uma identidade de interesses que até então não se fazia presente. Para perceber como a situação dos trabalhadores do café, sobretudo colonos e diaristas, piorou nos anos 1950, retomamos aqui um ponto importante levantado por Verena Stolcke. A historiadora nos leva a refletir sobre o salário mínimo em vigor naquela década e o salário rural real, percebido pelo trabalhador rural. Segundo ela, o êxito obtido pelos cafeicultores, ao vetar a proposta de Getúlio Vargas de unificar os salários urbanos e rurais, ou em outras palavras, de vetar a extensão da legislação trabalhista 
aos trabalhadores agrícolas, que ficaram excluídos, portanto, do salário mínimo obrigatório, foi para os trabalhadores, uma medida preocupante e desesperadora.

Os salários rurais nos anos 50 eram substancialmente mais baixos que os dos trabalhadores urbanos não qualificados. Além disso, a diferença entre o salário rural e o salário mínimo oficial aumentou consideravelmente nos anos 50 (STOLCKE, 1986, p. 174).

Outro fator que contribuiu para o fortalecimento dessa identidade também está relacionado com o salário: o não-cumprimento, pelos fazendeiros, da Lei 35.450 de 1o. de maio de 1954, que concedia aos trabalhadores rurais direito ao salário mínimo e ao pagamento de férias. Era comum, inclusive, os fazendeiros reterem mensalmente um saldo do salário, devolvendo-o ao trabalhador, quando este deixava de prestar serviço. Foram fatos como esses que levaram os trabalhadores a se reunir e discutir uma saída para a sua situação.

Odilon Martins, Waldevino Madeira e José Onofre Borges, colono e trabalhadores assalariados, respectivamente, foram os precursores dessas dicussões. Como conhecedores da realidade social nas fazendas e sítios, e incentivados pelo Partido Comunista Brasileiro (PCB) e pela União dos Trabalhadores de Londrina (UTL), propagaram a ideia de formar um sindicato. Para os líderes dos trabalhadores, a finalidade do sindicato era "garantir para o trabalhador agrícola a percepção de todas aquelas vantagens e o respeito àqueles direitos que lhe são assegurados pela CLT" (FOLHA DE LONDRINA, 1956a, p. 6).

Os trabalhadores rurais vislumbravam o sindicato como um veículo de luta, capaz de assegurar os seus direitos já garantidos por lei. Segundo José de Souza Martins, sabendo da existência de leis, ou de fragmentos de leis, que lhe concedem determinados direitos - como é o caso da CLT - os trabalhadores rurais se sentem incentivados a lutar, caso contrário, seria mais difícil eles se engajarem na luta (MARTINS, 1993). 
A ideia de formar um sindicato 'repercutiu célere' - para usar uma expressão da própria Folha de Londrina - entre a gente humilde do campo. Dada a situação crítica dos colonos e assalariados agrícolas, no mesmo estilo do quadro sombrio que caracterizava o panorama social do interior do país, o sindicato surgia como o símbolo da desejada, mas difícil, redenção econômico-social.

Dezenas de pequenas reuniões foram realizadas nas colônias das fazendas e sítios, onde as lideranças expunham os objetivos do sindicato e de que forma este poderia interceder junto aos patrões para melhorar o nível de vida dos trabalhadores. Os líderes sindicais, Odilon Martins, Waldevino Madeira e José Onofre Borges, eram sempre acompanhados pelo advogado Flávio Ribeiro, encarregado de esclarecer as questões jurídicas e explanar os direitos dos trabalhadores rurais que estavam garantidos na ínfima e excludente legislação social, bem como o papel que poderia exercer a Justiça do Trabalho na defesa desses escassos direitos (PRIORI, 1996).

Em 29 de Janeiro de 1956, com a participação de 300 trabalhadores, realizou-se no Cine Marabá de Londrina o Congresso de fundação do 'Sindicato dos Colonos e Assalariados Agrícolas de Londrina e Região'. A base territorial inicial do sindicato compreendia as cidades de Londrina, Rolândia, Cambé, Arapongas, Apucarana, Ibiporã, Sertanópolis e Bela Vista do Paraíso.

A receptividade dos trabalhadores rurais ao sindicato foi algo impressionante, talvez jamais visto na história do movimento sindical rural brasileiro. Em junho de 1956, o Jornal Terra Livre publicou matéria em que comentava a filiação dos trabalhadores ao sindicato.

O Sindicato dos Colonos e Assalariados Agrícolas de Londrina, recentemente fundado, vêm crescendo sem parar. Os diretores do sindicato, depois de estudarem as condições em que vivem os colonos e assalariados, resolveram lançar uma campanha pela aplicação da lei No. 35.450 de 1o. de maio de 1954, que dá direito aos trabalhadores rurais de receberem o salário mínimo e pelo pagamento das férias. 
Foi tão sentida esta campanha que, em apenas um mês, o número de associados aumentou de 300 para mais de 1.300, vindo de todas as fazendas e águas (TERRA LIVRE, 1956a, p. 12).

No mês seguinte, o mesmo jornal publicava matéria em que comentava que, até a data de 6 de julho de 1956, o sindicato contava com 8.085 filiados. Comentava ainda a matéria que cerca de 300 trabalhadores rurais passavam todos os dias pelo sindicato. Esse movimento obrigou o sindicato a transferir sua sede para um antigo cinema: o Cine Marabá. Em agosto de 1956, o Terra Livre comentava que o sindicato já tinha 15.000 sócios, e era considerado o maior do Brasil (TERRA LIVRE, 1956b).

De certa forma, não podemos confiar plenamente nesses dados apresentados pelo Jornal Terra Livre, pois, além de ser um jornal de divulgação das lutas dos trabalhadores rurais, editado pela ULTAB, sofria grande influência do Partido Comunista Brasileiro, que tendia a valorizar os sindicatos dirigidos por trabalhadores oriundos de seus quadros. Mas outras fontes indicavam que esse crescimento era significativo.

Em artigo intitulado $O$ problema do trabalhador rural, o colunista e deputado federal, Vieira Lins, discutia em A Folha de Londrina, a crescente sindicalização dos trabalhadores rurais no Norte do Paraná. A certa altura do artigo, enfatiza o deputado:

Um delegado especial, observando o que se passa no Norte do Paraná, afirma que cerca de 10.000 trabalhadores rurais acorreu ao chamamento de um sindicato rural, que os comunistas organizaram na região, alistando-se e concorrendo com dinheiro para a organização. Logo existe algo errado e doloroso para a vida do trabalhador rural: ele, para não morrer queimado, está saltando da ponte incendiada com o risco de morrer afogado (FOLHA DE LONDRINA, 1956b, p. 8). 
Nesse mesmo sentido, e preocupado com o alto índice de filiação de trabalhadores rurais ao sindicato, o então deputado federal por Londrina, Hugo Cabral, discursou na Câmara dos Deputados, dizendo que até aquela data - 05 de setembro de 1956 - já possuía o 'Sindicato de Colonos e Classes Assalariadas do Norte do Paraná' aproximadamente 40.000 filiados (FOLHA DE LONDRINA, 1956c).

A dúvida levantada em relação aos dados do Jornal Terra Livre poderia ser aplicada aos dados apresentados pelos deputados? Ao saber que o Jornal Terra Livre teria valorizado o número de trabalhadores rurais que procuraram o sindicato para se associar, o que poderia induzir a se acreditar que os dados dos deputados também foram, exageradamente, valorizados? Ou ambos os dados poderiam ser imbuídos de credibilidade?

Se anteriormente argumentamos que o Jornal Terra Livre valorizava os dados por ser um jornal de divulgação, influenciado pelo Partido Comunista Brasileiro, acreditamos ser a influência deste mesmo partido no sindicato os motivos utilizados pelos deputados para valorizarem os dados.

Conhecidamente, os dois deputados em questão eram adversos a qualquer ideologia que pudesse contrariar a ordem social estabelecida. O Deputado Hugo Cabral, inclusive, foi um grande cafeicultor, que não perdia uma oportunidade sequer para defender sua posição na tribuna da Câmara dos Deputados. A nossa argumentação é no sentido de que, ao divulgarem o grande índice de sindicalização rural, esses deputados atentavam para o 'perigo comunista', já que o sindicato era influenciado pelo PCB. Nesse caso, procuravam despertar as autoridades constituídas polícia, Justiça e Ministério do Trabalho - para esse 'perigo', incentivando o fechamento do sindicato e a punição dos seus dirigentes.

Embora se sabendo que houve uma valorização dos dados, haveria motivos para se acreditar na credibilidade desses dados? A pergunta soa como contraditória, mas não impossível de ser argumentada. Nesse caso, parece-nos importante raciocinar sobre essa 'impressionante' procura ao 
sindicato. Como frisamos anteriormente, as condições de trabalho não eram boas, as relações de trabalho institucionalizadas (o colonato) estavam em franca deterioração e a incerteza do trabalhador com relação ao seu emprego se renovava a cada vez que se aproximava o final do ano agrícola. Assim, os trabalhadores rurais eram incentivados ou se autoincentivavam a frequentarem o sindicato, na esperança, principalmente, de garantir o emprego.

A difícil realidade social em que vivia o trabalhador rural e a sua esperança no sindicato podem ser percebidas nestes versos declamados durante a II Conferência Nacional dos Trabalhadores Agrícolas, realizada em São Paulo no ano de 1954, e que praticamente virou hino na boca dos trabalhadores rurais do Norte do Paraná:

\author{
Nossas duras experiências \\ sofridas em tantos anos \\ Passando fome e miséria \\ desgostos e desenganos \\ É que abrimos nossos olhos \\ para traçar nossos planos \\ Vamos nos organizar \\ formar nosso sindicato \\ Pra por ele conseguir \\ custo de vida barato (PRIORI, 1996, p. 64-65).
}

O trabalhador rural, vítima dessa realidade social e sem o amparo de uma legislação eficiente, sentia-se como o 'grande excluído' da cidadania. E naquele momento percebia o sindicato como uma 'válvula de escape', como o único organismo de representação capaz de 'incluí-lo' no processo mais amplo de participação social, ou seja, na busca da plena cidadania ou em parte dela.

Nesse mesmo ano, mais quatro sindicatos foram fundados no Norte do Paraná: os sindicatos de Nova Fátima, Centenário do Sul, Maringá e Mandaguari. 


\section{A luta pela legitimidade e reconhecimento}

Os sindicatos fundados no Norte do Paraná durante o ano de 1956 não foram reconhecidos pelo Ministério do Trabalho. Embora a existência dos sindicatos não contemplasse os preceitos da legalidade exigidos pelo Estado, isso não quer dizer que não estavam impregnados de certa legitimidade. Havia, por certo, a preocupação dos dirigentes em legalizar os sindicatos, mesmo que isso significasse atrelá-los ao Ministério do Trabalho. No entanto, os trabalhadores rurais sindicalizados não estavam preocupados com esse processo. Para eles, o importante era a existência do sindicato como organismo de representação, que possibilitasse um espaço de participação política e de reinvidicação de suas necessidades sociais.

A respeito da legalidade do sindicato, formou-se um grande debate na região. Os empregadores rurais, preocupados com o rápido crescimento dos sindicatos, faziam intensa campanha pelo fechamento destes. Os palcos dessa campanha eram o Jornal Folha de Londrina e as Tribunas da Assembleia Legislativa do Estado e a Câmara dos Deputados. $\mathrm{O}$ argumento central dos empregadores rurais não era, em si, contra a existência do sindicato, e sim, contra aqueles que dirigiam o sindicato, ou seja, um grupo de 'agitadores subversivos' com o propósito de espalhar 'o ódio e a desordem' nas fazendas e sítios da região (FOLHA DE LONDRINA, 1956d).

O Deputado Estadual Rui Ferraz de Carvalho, em discurso na Assembleia Legislativa do Paraná, na sessão do dia 10 de setembro de 1956, retratou de forma enfática o pensamento dos empregadores rurais acerca do sindicato:

É apenas um pretexto para arregimentar colonos. A sua finalidade não é a defesa dos direitos do operário campesino, nem a melhoria das condições gerais em que vive - mas plantar a semente do ódio no coração daquela gente simples, atirá-la contra os patrões, estabelecer a luta de classes, reduzir a produção agrícola, aumentando assim a miséria, criando o descontentamento e o desespero, com 
o intuito de atraí-la para o seio do abraão do comunismo, onde se apregoa soluções salvadoras para todas as angustias humanas e o segredo capaz de realizar o bemestar e a felicidade dos homens sobre a terra (FOLHA DE LONDRINA, 1956d, p. 8).

Essa posição reflete a preocupação existente no seio da classe dominante rural com relação à política sindical desenvolvida pelo núcleo diretor do sindicato. Para os empregadores rurais, o sindicato deveria ser um órgão que tivesse os propósitos de "estudar, defender e coordenar os interesses econômicos dos trabalhadores" (FOLHA DE LONDRINA, 1956d, p. 8), com o objetivo de colaborar para o aprimoramento das relações de trabalho e a melhoria de suas condições de vida, mas nunca como o espaço de tomada de consciência das difíceis relações sociais.

Como os sindicatos do Norte do Paraná (principalmente os de Londrina, Nova Fátima, Centenário do Sul, Maringá e Manduaguari, sobretudo por serem os mais importantes) caminhavam no sentido contrário às expectativas dos empregadores, a saída encontrada por estes foi pedir a intervenção da polícia e da Justiça do Trabalho, para fechar os sindicatos e prender seus líderes. Depois da abertura dos Arquivos do DOPS, ocorrida na década de 1990, pudemos verificar como os sindicatos eram vigiados e controlados pela polícia política. Não há um sindicato do Estado do Paraná, seja ele urbano e rural, que não tenha sido contemplado com anotações em fichas e pastas naquele órgão policial.

Outro argumento, bastante consistente, contrário ao reconhecimento e à legalidade dos sindicatos de trabalhadores rurais do Norte do Paraná, foi emitido pelo Delegado Regional do Trabalho do Paraná, Senhor Antonio de Paula Filho.

A fim de fixar bem a nossa posição em face do problema, frisamos que não somos contrários à sindicalização rural. Nosso pensamento é o de que esses trabalhadores devem mesmo, organizar o seu sindicato, desde que obedeçam a lei e a ordem constituída. Nesse sentido, a nossa delegacia está aparelhada para orientar e esclarecer os honrados homens 
do campo, a fim de que a entidade que venha criar possa, efetivamente, cumprir suas finalidades, cooperando com os Poderes Públicos nas soluções dos problemas que lhes são afetos e promovendo a solidariedade social. Devem, na realidade, os trabalhadores da cidade e do campo pugnar por melhores condições de vida, mas sem agitação e sem comprometer a estabilidade social e econômica desta próspera região. Repetimos, pois, que, fiel ao seu programa de amparo aos homens de trabalho, a delegacia que temos a honra de dirigir está apta a atender aos legítimos anseios daqueles que desejam trabalhar sob a proteção de um sindicato bem orientado, de caráter nitidamente democrático, sem quaisquer inclinações extremistas. Um sindicato organizado desta forma só poderá concorrer para a solução do problema social, por isso que facilitará a convivência pacífica e harmoniosa entre empregados e empregadores, possibilitando, desse modo, a obtenção de uma constante melhoria do nível de vida dos assalariados agrícolas (FOLHA DE LONDRINA, 1956e, p. 4).

Merecem reflexão alguns pontos arrolados pelo Delegado do Trabalho. Primeiro, trata-se da questão do atrelamento do sindicato ao Ministério do Trabalho. Permitia-se aos trabalhadores rurais organizar os seus sindicatos, mas estes deveriam obedecer à 'lei e a ordem constituída', o que significa: o sindicato deveria submeter o seu estatuto ao crivo do Ministério, que também teria o controle econômico e financeiro do sindicato, além de possibilitar a intervenção ministerial toda vez que 'pessoas estranhas' ou 'doutrinas incompatíveis' viessem a interferir no bom andamento do sindicato. 'Pessoas estranhas', no caso, eram os simpatizantes do Partido Comunista e a 'doutrina incompatível' era o comunismo, fruto de campanha contrária intensa naquele período, motivado pela Guerra Fria que envolvia os blocos políticos liderados por EUA e União Soviética.

Em segundo lugar, o Ministério do Trabalho - durante o período que estamos analisando - só autorizava o funcionamento de um sindicato se este agisse conforme os interesses políticos daquele, que estavam pautados por uma prática política populista de manipulação das classes 
subalternas. O Estado, como um centro mediador, controlava as entidades sindicais, para que estas pudessem colaborar com o aprimoramento de uma solidariedade social que não comprometesse a estabilidade econômica e social do país (o tal medo do comunismo).

Pelos motivos já expostos, os empregadores rurais e a Delegacia Regional do Trabalho eram contrários ao reconhecimento do sindicato. Vimos, também, que, para os trabalhadores rurais em geral, pouco significado tinha a legalização ou não do sindicato. Quais motivos, então, conduziam os líderes dos sindicatos do Norte do Paraná a pedir o reconhecimento dos sindicatos? Sim, porque os dirigentes dos sindicatos entraram com diversos pedidos de reconhecimento no Ministério do Trabalho.

O próprio veículo de comunicação da ULTAB, o Jornal Terra Livre, alertava para a necessidade de se pedir no Ministério do Trabalho o reconhecimento do sindicato. Em janeiro de 1957, comentando o rápido crescimento do número de sindicatos rurais em todo o país, enfatizava que apenas fundar o sindicato não era suficiente, "é preciso que sejam reconhecidos, isto é, registrado no Ministério do Trabalho" JORNAL TERRA LIVRE, 1957, p. 12).

Condescendente com a política traçada pela ULTAB, em julho de 1956, a direção do 'Sindicato de Colonos e Assalariados Agrícolas de Londrina e Região' remeteu ao Ministério do Trabalho pedido em que solicitava o reconhecimento do sindicato. No mês de agosto, membros da diretoria do Sindicato de Londrina, do Sindicato de Maringá e do Sindicato de Centenário do Sul foram a São Paulo e depois ao Rio de Janeiro (ainda capital do Brasil) denunciar à grande imprensa, à Presidência da República, à Câmara dos Deputados e ao Senado a 'onda de violência, terror e perseguição' contra os trabalhadores e seus direitos e a morosidade do Ministério do Trabalho em reconhecer os sindicatos (JORNAL TERRA LIVRE, 1956c).

O próprio Deputado Hugo Cabral, em discurso à Câmara no início de setembro, comentava sobre a comissão de diretores dos sindicatos que 
havia se deslocado até a capital da República para pedir o reconhecimento do sindicato. No entanto, fazia um apelo

ao honrado Sr. Ministro do Trabalho, no sentido de não permitir tais registros sem primeiro tomar conhecimento do relatório que está sendo elaborado por um delegado especial enviado ao Norte do Paraná pelo supracitado Ministério (FOLHA DE LONDRINA, 1956b, p. 8).

No dia 05 de agosto de 1956, o sindicato dos trabalhadores rurais de Nova Fátima reuniu cerca de 1.000 trabalhadores em uma assembleia para aprovar o pedido de reconhecimento do sindicato junto ao Ministério do Trabalho. Nesse mesmo dia, com a presença de Geraldo Tibúrcio, presidente da ULTAB, foi realizada uma assembleia no sindicato dos trabalhadores rurais de Centenário do Sul, com o mesmo objetivo. Em dezembro de 1956, foi a vez do sindicato de Maringá encaminhar o pedido de reconhecimento (JORNAL TERRA LIVRE, 1956d).

Os motivos que levaram os dirigentes sindicais do Norte do Paraná a pedir o reconhecimento dos sindicatos podem ser analisados a partir de duas preocupações. Primeiro, do ponto de vista da classe: mesmo sendo contrários à política de atrelamento e de colaboração que interessava aos empregadores e ao Ministério do Trabalho, os dirigentes cederam ao pedir o reconhecimento. É certo que, com o reconhecimento, os trabalhadores rurais conseguiam ampliar a sua liberdade de ação reinvidicatória, possibilitando maior peso de influência nas decisões dos milhares 'processos trabalhistas' impetrados na Justiça do Trabalho ${ }^{17}$.

Em segundo lugar, o pedido de reconhecimento pode ser analisado do ponto de vista político. Nas décadas de 1950 e 1960, o movimento sindical rural no Estado do Paraná era disputado por duas tendências políticas: o Partido Comunista Brasileiro e a Igreja Católica (remetemos o leitor ao capítulo 13). Não dá para negar que os sindicatos de trabalhadores

17 Sobre os processo trabalhistas impetrados na Justiça por trabalhadores rurais, veja o livro O protesto do Trabalho, de um dos autores (PRIORI, 1996). 
rurais do Norte do Paraná estavam umbilicalmente vinculados à ULTAB, e que esta era influenciada politicamente pelo Partido Comunista Brasileiro. Como as outras tendências políticas procuravam agir dentro da legalidade, a avaliação que a ULTAB e o PCB faziam era de que, se fossem contrários à legalidade dos sindicatos, acabariam perdendo sua influência no seio do movimento sindical rural, abrindo maior espaço de atuação para a Igreja Católica e a Ação Popular (AP). Nesse caso, seria mais coerente administrar sindicatos controlados pelo Estado, que perder a sua influência dentro do movimento sindical e ficar alijados da luta social.

Os sindicatos do Norte do Paraná foram reconhecidos pelo Ministério do Trabalho somente no ano de 1962. Em agosto, foram reconhecidos os sindicatos de Maringá e Mandaguari. Em 20 de novembro de 1962, o Ministério do Trabalho publicou uma Portaria que facilitava a legalização de sindicatos rurais, surtindo efeito imediato. No dia 27 de novembro, saiu edital publicado pelo Ministério do Trabalho reconhecendo o sindicato de Londrina e os recém-fundados sindicatos de Nova Esperança e Jandaia do Sul (JORNAL TERRA LIVRE, 1962).

\section{$O$ sindicato e a resistência dos patrões}

Os empregadores rurais, assustados com o rápido crescimento dos sindicatos de trabalhadores rurais, trataram de arquitetar uma campanha no Estado, visando à desestruturação do movimento e à eliminação política dos seus líderes. Para isso desenvolveram duas estratégias: construir a imagem do movimento como uma 'ameaça comunista' e a imagem do trabalhador do campo como 'inocente', e, portanto, suscetível à ideologia comunista.

O espaço mais comum utilizado para divulgar essa campanha foram as páginas do Jornal Folha de Londrina e, depois, com a Fundação da Frente Agrária Paranaense, do Jornal Folha do Norte do Paraná. 
O próprio jornal Folha de Londrina foi consonante com a campanha, publicando diversos editoriais que pediam 'medidas exemplares' contra o movimento que avançava em 'proporções alarmantes'.

Em editorial publicado no dia 29 de junho de 1956, com o título sugestivo de $A$ agitação nos meios rurais, A Folha de Londrina conclamava as 'autoridades do estado' para tomar providências contra 'contumazes agitadores', que, a pretexto de promover a 'sindicalização do trabalhador rural', nada mais faziam do que derruir a produção agrícola, gerando graves consequências para o país, pois, "setores dos mais importantes, estão sendo abalados pelo trabalho solerte dos agentes da insídia e da traição" (FOLHA DE LONDRINA, 1956f, p. 2).

O ‘desequilíbrio econômico da região' e a queda da 'produção agrícola', provocados pela agitação nos meios rurais, são expressões que aparecem em quase todos os discursos e matérias jornalísticas daquele período. O que acarretaria esse ‘desequilíbrio', segundo seus interlocutores, seria o espírito de divergência de classe, que estava sendo incutido entre os trabalhadores rurais por 'perigosos subversivos'. É o que podemos notar nestas palavras do então Deputado Federal Hugo Cabral:

\footnotetext{
Como se não bastasse as calamidades que, periodicamente, se abatem sobre nós, como que experimentando a extensão de nossas energias e amor à terra, no momento se processa nesta zona o mais audacioso e insólito movimento comunista de que temos memória, movimento criminoso porque visa quebrar a harmonia que sempre existiu entre colonos e lavradores (FOLHA DE LONDRINA, 1956g, p. 3).
}

Essa harmonia, que retrata o deputado, vinha sendo quebrada por dois aspectos: o grande número de ações trabalhistas impetradas na Justiça do Trabalho por trabalhadores rurais e a organização do sindicato na região. O combate ao comunismo, que a classe dominante, sobretudo a rural, vinha propagando, na realidade era um combate a qualquer manifestação oriunda das 'classes subalternas', nesse caso, os trabalhadores rurais. 
Em 19 de maio de 1956, A Folha de Londrina publicou uma matéria que dá uma boa ideia de como os empregadores rurais concebiam a movimentação dos trabalhadores rurais rumo ao sindicato: como caso de polícia. A matéria intitulada Denúncia da lavoura contra a articulação comunista em Londrina descrevia um manifesto que diversos empregadores rurais entregaram ao delegado de polícia, para que este apurasse as diversas atividades subversivas de comunistas em Londrina e região. O manifesto dizia que diversos comunistas vinham se reunindo constantemente no Cine Marabá e no Edifício Autolon, e que, nessas reuniões, usando de 'artimanhas, falsidades e mentiras', envenenavam o espírito de pacatos colonos, transformando-os em 'elementos desordeiros e rebeldes', com evidentes prejuízos para a classe agrícola e a 'harmonia das relações' entre patrões e empregados (FOLHA DE LONDRINA, 1956h) Notamos, aqui, a confirmação da tese de que os empregadores rurais construíram a imagem do trabalhador rural como 'ignorante', e, portanto, presa fácil dos agitadores comunistas.

A campanha contra os sindicatos, evasivamente substanciada no discurso anticomunista, não se limitou apenas ao cenário regional. $\mathrm{O}$ desespero dos grandes cafeicultores com o rápido crescimento e fortalecimento dos sindicatos era tanto, que levou tais cafeicultores a contratar jornais de grande circulação nacional para divulgar suas ideias. Os Diários Associados, por exemplo, publicavam, quase que diariamente, notícias de assembleias de trabalhadores rurais, acusando estes de 'baixo nível mental' e de querer atear fogo nas lavouras de café.

O Congresso Nacional era outro espaço importante utilizado na campanha antissindicato. Na sua tribuna, Othon Mader e Hugo Cabral discursavam, pedindo a intervenção policial para fechar o sindicato, o qual teria por objetivo "promover a discórdia entre patrões e empregados, principalmente na zona rural" (FOLHA DE LONDRINA, 1956i).

Como que em resposta aos discursos dos deputados e senadores, o Jornal Terra Livre publicou longa matéria intitulada Deputado não cumpre 174 leis, em que acusava o Deputado Hugo Cabral de cometer diversas 
arbitrariedades em suas fazendas contra trabalhadores. Segundo o jornal, o deputado cobrava multa dos trabalhadores que chegassem ao serviço depois da 06 h da manhã; idem para quem saía antes das 06 h da tarde; jornada de 12 h; cobrança de transporte para pessoas doentes; não fornecimento de leite às crianças, etc, além de perseguição aos empregados que se sindicalizavam: “o deputado o que faz é ir para a Câmara Federal pedir polícia e negar as conquistas dos trabalhadores agrícolas" (JORNAL TERRA LIVRE, 1956b, p. 8). Há, evidentemente, exageros nas palavras do jornal.

Vimos até aqui as formas legais que os empregadores rurais utilizavam para protestar contra os sindicatos de trabalhadores rurais, ou seja, a imprensa, a Justiça, as tribunas das casas legislativas, etc. No entanto, houve casos mais extremados em que os patrões se utilizaram de meios ilegais, como a invasão aos sindicatos, apedrejamento, incêndios, etc.

Excluíndo-se as diversas invasões que o Sindicato dos Colonos e Assalariados Agrícolas de Londrina sofreu, inclusive o seu fechamento por determinação da Justiça em 27 de Agosto de 1956 (FOLHA DE LONDRINA, 1956j), os casos mais graves foram os ataques aos sindicatos de Mandaguari e Jandaia do Sul.

Em Jandaia do Sul havia uma disputa entre trabalhadores e patrões pelo controle do sindicato. Ao mesmo tempo em que trabalhadores rurais fundaram o seu sindicato, os patrões haviam fundado um sindicato fantasma, cujo nome era 'Sindicato de Trabalhadores Rurais de Jandaia do Sul' e tinha como presidente o proprietário Antenor Rodrigues Simões, dono de vastas áreas de terras. Tanto patrões como empregados haviam pedido o reconhecimento no Ministério do Trabalho. Como a lei de sindicalização rural em vigor não permitia a pluralidade sindical, o Ministério do Trabalho acabou dando ganho de causa aos trabalhadores rurais, reconhecendo o seu sindicato em 27 de novembro de 1962.

No entanto, já no dia de sua fundação, 14 de setembro de 1962, o sindicato sofreu um apedrejamento, com grandes danos materiais, saindo feridos diversos policiais, inclusive o delegado de polícia e o escrivão, que 
faziam a segurança da assembleia (JORNAL TERRA LIVRE, 1962). O apedrejamento foi articulado pelas pessoas que dirigiam o suposto 'sindicato fantasma'. Aliás, fundar 'sindicatos fantasmas' foi um ato bastante usual dos latifundiários e de seus cúmplices, tanto no Paraná, como também no Estado de São Paulo. Segundo o Jornal Terra Livre, esses 'sindicatos fantasmas' geralmente eram fundados "por um patrão, um comerciante interessado na política do latifúndio, e muitas vezes fundados pelos padres, com a finalidade de desviar a luta dos homens do campo e desenvolver o peleguismo nas organizações e entidades rurais de classe" (JORNAL TERRA LIVRE, 1962).

Em fevereiro de 1963, o Jornal Terra Livre publicava matéria sobre a invasão do sindicato de Mandaguari. Segundo o jornal, ao amanhecer do dia 16 de janeiro de 1963, o sindicato teve suas portas arrombadas por 'elementos terroristas', pagos pelos latifundiários. O sindicato foi invadido por capangas que levaram todo os papéis dos arquivos, com o objetivo de desorganizar os trabalhadores rurais, "impedindo a sua organização, garantida por lei” (JORNAL TERRA LIVRE, 1963, p. 12). Nessa mesma data, foram também invadidas a Associação dos Ensacadores e Carregadores de Café, a Associação dos Empregados no Comércio e a União Geral dos Trabalhadores de Mandaguari.

Como vimos ao longo do texto, a luta política pelo reconhecimento dos direitos sociais e pela livre organização sindical dos trabalhadores rurais foi travada com muito embate e conflito. Eram tempos difíceis, sem lugar para a inocência.

\section{Referências}

FOLHA DE LONDRINA. Londrina, 20 nov. 1956a.

FOLHA DE LONDRINA. Londrina, 19 ago. 1956b.

FOLHA DE LONDRINA. Londrina, 07 set. 1956c.

FOLHA DE LONDRINA. Londrina, 16 set. 1956d. 
FOLHA DE LONDRINA. Londrina, 22 jul. 1956e.

FOLHA DE LONDRINA. Londrina, 29 jun.1956f.

FOLHA DE LONDRINA. Londrina, 21 jul. 1956g.

FOLHA DE LONDRINA. Londrina, 19 maio 1956h.

FOLHA DE LONDRINA. Londrina, 13 jul. 1956i.

FOLHA DE LONDRINA. Londrina, 28 ago. 1956j.

JORNAL TERRA LIVRE. São Paulo, n. 49, 1954.

JORNAL TERRA LIVRE. São Paulo, n. 65, jun. 1956a.

JORNAL TERRA LIVRE. São Paulo, n. 69, ago. 1956b.

JORNAL TERRA LIVRE. São Paulo, n. 70, jul. 1956c.

JORNAL TERRA LIVRE. São Paulo, n. 75, dez. 1956d.

JORNAL TERRA LIVRE. São Paulo, n. 76, jan. 1957.

JORNAL TERRA LIVRE. São Paulo, n. 117, dez. 1962.

JORNAL TERRA LIVRE. São Paulo, n. 120, mar. 1963.

MARTINS, José de Souza. Caminhada no chão da noite. São Paulo: Hucitec, 1989.

MARTINS, José de Souza. A chegada do estranho. São Paulo: Hucitec, 1993.

PRIORI, Angelo. O protesto do trabalho: história das lutas sociais dos trabalhadores rurais. Maringá: Eduem, 1996.

STOLCKE, Verena. Cafeicultura: homens, mulheres e capital (1850-1980). São Paulo: Brasiliense, 1986. 